\title{
(Taylor) Rules versus Discretion in U.S. Monetary Policy ${ }^{*}$
}

\author{
Alex Nikolsko-Rzhevskyy ${ }^{\dagger}$ \\ Lehigh University \\ Ruxandra Prodan ${ }^{\S}$ \\ University of Houston
}

\author{
David H. Papell ${ }^{*}$ \\ University of Houston
}

July 19, 2013

\begin{abstract}
The Taylor rule has been the dominant metric for monetary policy evaluation over the past 20 years, and it has become common practice to identify periods where policy either adheres closely to or deviates from the Taylor rule benchmark. The purpose of this paper is to identify (Taylor) rules-based and discretionary eras solely from the data so that knowledge of subsequent economic outcomes cannot influence the choice of the dates. We define Taylor rules-based and discretionary eras by smaller and larger Taylor rule deviations, the absolute value of the difference between the actual federal funds rate and the federal funds rate prescribed by the original Taylor rule, and use tests for multiple structural changes and Markov switching models to identify the eras. Monetary policy in the U.S. is characterized by a Taylor rulesbased (low deviations) era until 1974, a discretionary (high deviations) era from 1974 to about 1985, a rules-based era from about 1985 to 2000, and a discretionary era from 2001 to 2008. The Taylor rule deviations are about three times as large in the discretionary eras than in the rules-based eras and are almost four times larger in the most discretionary era (1974 to 1984) than in the least discretionary era (1985 to 2000). With the Markov switching models, which allow for regime changes at the beginning and end of the sample, we also identify a discretionary era from 1965 to 1968 and a rules-based era in 2006 and 2007. The discretionary and rules-based eras closely correspond to periods where the Taylor rule deviations are above and below two percent.
\end{abstract}

\footnotetext{
${ }^{*}$ We are grateful to seminar participants at Emory University for helpful comments and discussions. The data used in the paper can be downloaded at https://sites.google.com/site/alexrzhevskyy/files/data_rules_discretion.zip.

${ }^{\dagger}$ Department of Economics, Lehigh University, Bethlehem, PA 18015. Tel: +1 (901) 678-4627 Email: alex.rzhevskyy@gmail.com

${ }^{*}$ Department of Economics, University of Houston, Houston, TX 77204-5882. Tel/Fax: +1 (713) 743-3807/3798. Email: dpapell@uh.edu

${ }^{\S}$ Department of Economics, University of Houston, Houston, TX 77204-5882. Tel/Fax: +1 (713) 743-3836/3798.

Email: rprodan@uh.edu
} 


\section{Introduction}

Comparison of rules-based and discretionary monetary policy has been central to macroeconomics since the publication of the seminal Kydland and Prescott (1977) article. While there are a great variety of policy rules, the Taylor (1993) rule, where the Fed raises the interest rate when inflation rises above target and/or output rises above potential, has received the most attention. Questions ranging from whether Fed policy was too stimulative in the 1970s, on track in the 1980s and 1990s, and again too stimulative in the 2000s, contributing to the Great Inflation, Great Moderation, and the Great Recession, respectively, have all been extensively analyzed in the context of the Taylor rule.

In a recent essay, "Monetary Policy Rules Work and Discretion Doesn't: A Tale of Two Eras," Taylor (2012a) identifies the late 1960s and 1970s as a period of discretionary policy, 1980 to 1984 as a transition, 1985 to 2003 as the rules-based era, and 2003 - 2012 (and possibly beyond) as the ad hoc era. He argues that economic performance in the rules-based period was vastly superior to that in the ad hoc period and, while correlation does not prove causation, the timing of events supports the interpretation that (good or bad) policy causes (good or bad) economic performance rather than causation going in the opposite direction.

Identification of monetary policy eras is fraught with peril. Whatever the rule, there is always the danger that, since the economic performance outcomes are known, periods with good economic performance will be identified as rules-based while periods of bad economic performance will be characterized as ad hoc.

In this paper, we propose and implement a statistical methodology for dividing monetary policy into Taylor-rules-based and discretionary eras. We first calculate Taylor rule deviations, the difference between the federal funds rate and the interest rate implied by the Taylor (1993) rule, 1.0 plus 1.5 times inflation plus 0.5 times the output gap, which assumes that the target inflation rate and the equilibrium real interest rate both equal 2.0 percent. Next, using tests for structural change and Markov switching methods, we identify Taylor rules-based eras where the deviations are small and discretionary eras where the deviations are large. With both methods, neither the number nor the dates of the regimes is specified a priori, and so prior knowledge of economic outcomes cannot affect the results.

Calculating Taylor rule deviations necessitates some choices and compromises. We want to use real-time data that was available to policymakers when interest rate decisions were made 
for as long a period as possible. While it would be ideal to use internal Fed (Greenbook) output gaps, these are only available from 1987 to 2007 . We therefore use real-time real GDP (or GNP) and GDP (or GNP) deflator data from the Philadelphia Fed starting in 1965:Q4, when the data begins, and ending in 2008:Q4, when the Federal funds rate hit the zero lower bound. We calculate inflation as the percentage change in the GDP deflator and the output gap as the deviation from a real-time quadratic trend. We show that the real-time quadratic detrended output gaps provide a closer approximation to "reasonable" real-time output gaps, calculated using Okun's Law, than alternatives including real-time linear and Hodrick-Prescott detrending.

We identify monetary policy eras with Bai and Perron (1998) tests for multiple structural breaks, allowing for changes in the mean of the Taylor rule deviations. Commencing with the start of the data in 1965:4, monetary policy in the U.S. is characterized by a Taylor rules-based (low deviations) era until 1974:Q2, followed by a discretionary (high deviations) era from 1974:Q3 - 1984:Q4, a rules-based era from 1985:Q1 - 2000:Q4, and another discretionary era from 2001:Q1 to the end of the sample in 2008:Q4. The dates of the breaks are unchanged if tests for multiple restricted structural changes of Perron and Qu (2006), which restrict the mean of the deviations in the two rules-based and two discretionary eras to be the same, are used instead. During the discretionary periods of the 1970s and 2000s, the Federal funds rate is consistently below the rate implied by the Taylor rule while, in the early 1980s, the actual rate is above the implied Taylor rule rate. The size of the deviations in the discretionary eras is more than three times as large as in the rules-based eras.

We also use the Markov switching methods of Hamilton (1989), where the monetary policy eras are defined by high and low Taylor rule deviation states. Most of the regime dates are close to those found with tests for structural change. The first Taylor rules-based (low deviations) era ends in 1974:Q3, followed by a discretionary (high deviations) era from 1974:Q4 - 1986:Q1, a rules-based era from 1986:Q2 - 2001:Q1, and another discretionary era from 2001:Q2 to 2006:Q2. The differences in the results between the methods occur at the beginning and end of the sample. With Markov switching, there is a discretionary (high deviations) era from 1965:Q4 - 1968:Q4, a short low deviations era from 2006:Q3 - 2007:Q4, and an even shorter high deviations era from 2008:Q1 - 2008:Q4. ${ }^{1}$ The discretionary and rules-based eras

\footnotetext{
${ }^{1}$ Even these differences may be overstated, as the tests for structural change do not allow for breaks in the first and last fifteen percent of the data.
} 
closely correspond to periods where the Taylor rule deviations are above and below two percent. As with the tests for structural change, the size of the deviations is more than three times as large in the discretionary eras than in the rules-based eras.

It is important to be clear regarding what this paper is and is not about. We are not providing new evidence that monetary policy rules work better than discretion, a topic that has been the subject of extensive research. Instead, we use two well-known econometric methodologies, structural change tests and Markov switching models, to identify Taylor rulesbased and discretionary eras from the data instead of choosing the eras a priori. Since our classification of rules-based and discretionary eras is not influenced by economic outcomes, it provides an improved basis for dating rules-based and discretionary eras and, therefore, for evaluating the effects of monetary policy rules versus discretion.

\section{Taylor Rule Deviations with Real-Time Data}

Taylor (1993) proposed the following monetary policy rule,

$$
i_{t}=\pi_{t}+\phi\left(\pi_{t}-\bar{\pi}\right)+\not y_{t}+R
$$

where $i_{t}$ is the target level of the short-term nominal interest rate, $\pi_{t}$ is the inflation rate, $\bar{\pi}$ is the target level of inflation, $y_{t}$ is the output gap, the percent deviation of actual real GDP from an estimate of its potential level, and $R$ is the equilibrium level of the real interest rate. Taylor postulated that the output and inflation gaps enter the central bank's reaction function with equal weights of 0.5 and that the equilibrium level of the real interest rate and the inflation target were both equal to 2 percent, producing the following equation,

$$
i_{t}=1.0+1.5 \pi_{t}+0.5 y_{t}
$$

We define Taylor rule deviations as the absolute value of the difference between the actual federal funds rate and the interest rate target implied by the Taylor rule with the above coefficients. A rules-based era would have small deviations while a discretionary era would have large deviations. In our empirical work below, "large" and "small" are determined endogenously in the context of our statistical methods.

The implied Taylor rule interest rate is calculated from data on inflation and the output

gap. Following Orphanides (2001), the vast majority of research on the Taylor rule uses real-time data that was available to policymakers at the time that interest rate setting decisions were made. 
The Real-Time Data Set for Macroeconomists, originated by Croushore and Stark (2001) and maintained by the Philadelphia Fed, contains vintages of nominal and real GDP (GNP before December 1991) data starting in 1965:4, with the data in each vintage extending back to 1947:1.

We construct inflation rates as the year-over-year change in the GDP Deflator, the ratio of nominal to real GDP. While the Fed has emphasized different inflation rates at different points in time, real-time GDP inflation is by far the longest available real-time inflation series. An alternative would be to splice together a series from the emphasized inflation measures at different points in time. Even if it was possible to construct such a series with real-time data (and it is not), this would risk finding spurious evidence of different eras based on spliced data.

In order to construct the output gap, the percentage deviation of real GDP around potential GDP, the real GDP data needs to be detrended. We use real-time detrending, where the trend is calculated from 1947:1 through the vintage date. For example, the output gap for 1965:4 is the deviation from a trend calculated from 1947:Q1 to 1965:Q3, the output gap for 1966:Q1 is the deviation from a trend calculated from 1947:Q1 to 1965:Q4, and so on, replicating the information available to policymakers. ${ }^{2}$

The three leading methods of detrending are linear, quadratic, and Hodrick-Prescott (HP). Real-time output gaps using these methods are depicted in Figure 1. In contrast with output gaps constructed using revised data, where the trends are estimated for the entire sample, there is no necessity for the positive output gaps to equal the negative output gaps. While there are considerable differences among the gaps, the most negative output gaps correspond closely with NBER recession dates for all three methods.

Which real-time output gap best approximates the perceptions of policymakers over this period? We use Okun's Law, which states that the output gap equals a (negative) coefficient times the difference between current unemployment and the natural rate of unemployment, to construct "rule-of-thumb" output gaps based on real-time unemployment rates, perceptions of the natural rate of unemployment, and perceptions of the Okun's Law coefficient. We focus on the quarters of peak unemployment associated with various recessions, and investigate the congruence between real-time Okun's Law output gaps and real-time output gaps computed with various detrending methods.

\footnotetext{
${ }^{2}$ The lag reflects the fact that GDP data for a given quarter is not known until after the end of the quarter.
} 
The peak unemployment rates associated with the two recessions of the 1970 s were $6.0 \%$ in 1971:Q4 and 8.9\% in 1975:Q2. Using a variety of sources, Nikolsko-Rzhevskyy and Papell (2012) identify natural rates of unemployment of 5.2\% in 1971 and 5.5\% in 1975 and an Okun's Law coefficient of 3.0 as plausible estimates for the times. Using these numbers, the real-time Okun's Law output gap is for 1972:Q1, (assuming a one-quarter lag before the GDP data was released), is $-2.4 \%$. This is close to the output gaps constructed by real-time linear and quadratic detrending, $-2.2 \%$ and $-2.9 \%$, respectively, but higher than the real-time HP filtered gap of $0.0 \%$. For 1975:Q3, the real-time Okun's Law output gap is $-10.2 \%$. This is again close to the output gaps constructed by real-time linear and quadratic detrending, $-10.8 \%$ and $-10.4 \%$, respectively, but higher than the real-time HP filtered gap of $-5.9 \%$.

A similar pattern is observed for the early 1980s, where the peak unemployment rate associated with the 1980 and 1982 recessions is 10.7\% in 1982:Q4. According to the 1983 Economic Report of the President, between 6 and 7 percent of unemployment for 1982 was structural, and Gordon (1984) identifies an Okun's Law coefficient of $-2.5 .^{3}$ Using $6.5 \%$ as the natural rate of unemployment, the real-time Okun's Law output gap for 1983:Q1 was -10.5\%, higher than the real-time linear, quadratic, and HP gaps of $-9.72 \%,-6.49 \%$, and $-4.58 \%$, respectively. As in the 1970s, the Okun's Law gap is closer to the linear and quadratic gaps than to the HP gap.

During the 1970s and early 1980s, the Okun's Law metric does not provide a basis to choose between the real-time linear and quadratic output gaps. More recently, however, real-time linear output gaps fail the rule-of-thumb test. As shown in Figure 1, the gap becomes negative in 1974:Q2 and, with the exception of 1999:Q4 and 2000:Q1, is negative for every quarter in the ensuing 34 years. This is a consequence of the well-known productivity slowdown, where growth rates declined starting in 1973 relative to the period between World War II and 1972. The HP gaps do not fare much better. The gaps for the 1990 and 2001 recessions are almost as large as for the 1980 and 1982 recessions, and the gap is close to zero at the end of 2008 . For these reasons, we use real-time quadratic detrending to construct the output gaps for the Taylor rule for the entire sample.

\footnotetext{
${ }^{3}$ The 1983 Economic report of the President was completed in February 1983 and the Preface to Gordon (1984) is dated September 1983, so these are good sources of real-time data for 1983:1.
} 
Taylor rule deviations are depicted in Figure 2. Panel A shows the actual federal funds rate and the Taylor rule rate implied by Equation (2). Panel B illustrates the difference between the actual and implied rates, and Panel $\mathrm{C}$ depicts the Taylor rule deviations, the absolute value of the differences shown in Panel B. Figure 2 summarizes some well-known results from research that uses Taylor rules to conduct normative monetary policy evaluation. Compared to the implied Taylor rule rate, the actual federal funds rate is too low in the 1970s, too high in the early 1980s, and too low in the early-to-mid 2000s. This is consistent with Taylor (1999), who characterized the 1970s and early 1980s as periods of policy mistakes, although he qualified the characterization of the early 1980s as a mistake on the grounds that the high interest rates were necessary to bring down inflation, and Taylor (2007), who argued that the housing boom was caused by too low interest rates in 2002-2006.

\section{Structural Change}

In order to identify monetary policy eras, we use Bai and Perron $(1998,2003)$ tests for multiple structural breaks, allowing for changes in the mean of the Taylor rule deviation. We consider the following multiple linear regressions with $m$ structural breaks $(m+1$ regimes):

$$
d_{t}=\gamma_{0}+\gamma_{1} D U_{1 t}+\gamma_{2} D U_{2 t}+\ldots \gamma_{m} D U_{m t}+u_{t}
$$

where $d_{t}$ are the Taylor rule deviations from Equation (2) and $D U_{m t}=1$ if $t>T b_{t}$ and 0 otherwise, for all values of the break points $T b_{t}$.

The estimated break points are obtained by a global minimization of the sum of squared residuals (SSR). We consider the sequential test of $l$ versus $l+1$ breaks, labeled $F t(l+1 \mid l)$. For this test the first $l$ breaks are estimated and taken as given. The statistic sup $F t(l+1 \mid l)$ is then calculated as the maximum of the $F$-statistics for testing no further structural change against the alternative of one additional change in the mean when the break date is varied over all possible dates. The procedure for estimating the number of breaks suggested by Bai and Perron is based on the sequential application of the sup Ft $(l+1 \mid l)$ test. The procedure can be summarized as follows. Begin with a test of no-breaks versus a single break. If the null hypothesis of no breaks is rejected, proceed to test the null of a single break versus two breaks, and so forth. This process is repeated until the statistics fail to reject the null hypothesis of no additional breaks. The 
estimated number of breaks is equal to the number of rejections. Following Bai and Perron's (2003b) recommendation to achieve test with correct size in finite samples, we use a value of the trimming parameter $\varepsilon=0.15$ and a maximum number of breaks $m=5$. The test has a nonstandard asymptotic distribution and critical values are provided in Bai and Perron (2003b). ${ }^{4}$

Using the above test we find three significant breaks in the mean of the Taylor rule deviation and, therefore, four regimes. The results are reported in Table 1 and illustrated in Figure 3. The timing of the breaks occurs in 1974:Q3, 1985:Q1 and 2001:Q1. Based on the estimated coefficients on dummy variables we identify four regimes, with the following estimated mean of deviations $\left(\mu_{i}\right)$ in each regime: $\mu_{1}=\gamma_{0}=1.47$ for $\mathrm{t}<1974: \mathrm{Q} 3, \mu_{2}=\gamma_{0}+\gamma_{1}=$ 3.30 for 1974:Q4 $<\mathrm{t}<1984: \mathrm{Q} 4, \mu_{3}=\gamma_{0}+\gamma_{1}+\gamma_{2}=0.85$ for 1985:Q1 $<\mathrm{t}<2000: \mathrm{Q} 4$ and $\mu_{4}=$ $\gamma_{0}+\gamma_{1}+\gamma_{2}+\gamma_{3}=2.30$ for 2001:Q1 $<\mathrm{t}<2008: \mathrm{Q} 4$. Consequently, starting in 1965:4, monetary policy in the U.S. is characterized by a Taylor rules-based (low deviations) era until 1974:Q2, followed by a discretionary (high deviations) era from 1974:Q3 - 1984:Q4, a rules-based era from 1985:Q1 - 2000:Q4, and another discretionary era from 2001:Q1 to the end of the sample in 2008:Q4. The largest deviations were from 1974 to 1984 and the smallest deviations were from 1985 to $2000 .^{5}$

One question that naturally arises is whether the breaks define distinct regimes. In order to answer this question, we report confidence intervals around the break dates in Table 1 . The 95 percent confidence intervals are all smaller than three years and do not overlap, providing additional support for our characterization of low and high deviations eras.

While the Bai and Perron tests identify statistically significant changes in the mean of the Taylor rule deviations, they do not determine whether the means for the two higher deviations periods are statistically different from the means in the two lower deviations periods. In order to assess whether the mean of the deviations in the two rules-based and the two discretionary eras are significantly different we use the Perron and Qu (2006) restricted structural change test. We

\footnotetext{
${ }^{4}$ Bai and Perron (2003a) use an efficient algorithm for estimating the break points based on dynamic programming techniques. They also propose a methodology for identifying breaks if the no-break null is not rejected against the single-break methodology, which is not needed for this paper.

${ }^{5} \mathrm{We}$ also estimated break points where the Taylor rule deviations were calculated using an output gap coefficient of 1.0 instead of 0.5 , which is consistent with the specification in Rudebusch (2010). The major difference was that the first discretionary era starts in 1978:Q4 instead of 1974:Q3. This does not accord with the inflationary experience of the 1970s.
} 
add two constraints to the multiple linear regressions model (3) in which we assume that there are three structural breaks (four regimes):

$$
\gamma_{1}+\gamma_{2}=0
$$

and

$$
\gamma_{2}+\gamma_{3}=0
$$

By imposing these constraints, we restrict the mean of the deviations in the two rulesbased eras to be the same $\left(\mu_{1}=\mu_{3}\right)$ and the two discretionary eras to be the same $\left(\mu_{2}=\mu_{4}\right)$. In order to test for the existence of structural change, we use the supremum F-test of no structural change $(\mathrm{m}=0)$ against an alternative of $\mathrm{m}=$ three restricted structural changes. The estimates of the restricted break dates are constructed as the global minimizers of the restricted SSR using the method of Bai and Perron (2003b). As previously, we use a value of the trimming parameter $\varepsilon=0.15$. Asymptotic critical values are simulated. ${ }^{6}$

The results are reported in Table 2. Using the tests for multiple restricted structural changes of Perron and Qu (2006), we find that the break dates are identical with the ones previously found when testing for unrestricted changes: 1974:Q3, 1985: Q1 and 2001:Q1. ${ }^{7}$ We identify four regimes with the following coefficients: $\mu_{1}=\mu_{3}=1.075$ for $\mathrm{t}<1974: \mathrm{Q} 3$ and 1985:Q1 < $<$ 2000:Q4 and $\mu_{2}=\mu_{4}=2.88$ for 1974:Q4 < $<1984: \mathrm{Q} 4$ and 2001:Q1 < $<$ 2008:Q4. The deviations in the discretionary eras are significantly higher than the deviations in the rules-based eras, as the null of no structural change can be rejected against the alternative of three restricted structural changes at the one percent significance level.

The differences between the rules-based and discretionary eras are economically as well as statistically significant. The Taylor rule deviations are almost three times larger in the discretionary eras than in the rules-based eras using Perron and $\mathrm{Qu}$ tests and are almost four times larger in the most discretionary era (1974 to 1984) than in the least discretionary era (1985 to 2000) using Bai and Perron tests.

It is often asserted that, because monetary policymaking is forward looking, Taylor rules should be estimated using forecasted instead of realized variables. We investigate the implications for our results by estimating Bai and Perron models with four-quarter-ahead Greenbook inflation forecasts, which are available from 1973:Q3 - 2007:Q4, complemented by

\footnotetext{
${ }^{6}$ A code written in the Gauss language is available from Perron and Qu (2006).

${ }^{7}$ Because the break dates in Table 2 are identical to those in Table 1, they are also depicted by Figure 3.
} 
SPF forecasts for 2008:Q1-2008:Q4 for consistency with the other models. ${ }^{8}$ The results are reported in Table 3 and depicted in Figure 4. The breaks are 1980:Q3, 1985:Q3, and 2001:Q1. Because the data starts in 1973:Q3, we cannot identify the start of the 1970s discretionary era. There is a high deviations era through 1980:Q2, a higher deviations era from 1980:Q3 1985:Q2, a low deviations era from 1985:Q3 - 2000:Q4, and a high deviations era from 2001:Q1- 2008:Q4. The confidence intervals do not overlap. Over the same span of data, the results with forecasted inflation are similar to those with realized inflation.

\section{Markov Switching}

We proceed to apply the Markov Switching (MS) model of Hamilton (1989) to the Taylor rule deviations series. While a simple two-state MS model allows for a large number of potential regime changes, the dynamics is limited to only the two regimes as the economy switches back and forth between them.

As before, $d_{t}$ denotes the absolute deviation of the funds rate from the 1993 Taylor rule. The model postulates the existence of an unobserved variable $\left(s_{t}\right)$ that takes on two values, 1 and 2 , and characterizes the "state" (or regime) that the policy is in at time $t$. When $s_{t}=1$, the Taylor rule deviation $d_{t}$ is distributed $N\left(\mu_{1}, \sigma_{1}{ }^{2}\right)$, whereas when $s_{t}=2, d_{t}$ is distributed $N\left(\mu_{2}, \sigma_{2}{ }^{2}\right)$. If $\mu_{l<}$ $\mu_{2}$, we say that in regime 1 the Fed was running a rules-based monetary policy, while in regime 2 the policy was discretionary. Thus the model postulates that:

$$
d_{t}=\mu_{S t}+\varepsilon_{S t}
$$

where the unobserved state variable $\left(s_{t}\right)$ is governed by the following transition probabilities:

$$
\begin{aligned}
& \operatorname{Pr}\left[s_{t}=1 \mid s_{t-1}=1\right]=p_{11} \\
& \operatorname{Pr}\left[s_{t}=2 \mid s_{t-1}=2\right]=p_{22}
\end{aligned}
$$

Large values of $p_{s s}$ generate inertia, resulting in persistent monetary policy regimes. The parameter vector $\theta=\left\{\mu_{1}, \mu_{2}, \sigma_{1}, \sigma_{2}\right.$, and $\left.p_{11}, p_{22}\right\}$ can be estimated by maximum likelihood using

\footnotetext{
${ }^{8}$ While one-quarter-ahead inflation forecasts are available earlier, one-quarter inflation (realized or forecasted) is much noisier than the annualized inflation rates normally used to estimate Taylor rules.
} 
the procedure described in Hamilton (1989). The results are available in Table 4 with the state distribution presented in Figure 5.

The algorithm identifies two separate persistent regimes with the estimated probabilities $\mathrm{p}_{11}=0.96$ and $\mathrm{p}_{22}=0.95$. As with the tests for structural change, the results are economically as well as statistically significant. The size of the deviations is more than three times as large in the discretionary eras $\left(\mu_{2}=2.92\right)$ than in the rules-based eras $\left(\mu_{1}=0.81\right)$, with the difference between the regimes being highly significant. ${ }^{9}$ If we look at the estimated state distribution, most of the regime dates are close to those found with tests for structural change. The first Taylor rulesbased ( $\mathrm{S}=1$, low deviations, small $\mu$ ) era ends in 1974:Q3, followed by a discretionary ( $\mathrm{S}=2$, high deviations, large $\mu$ ) era from 1974:Q4 - 1986:Q1, a rules-based era from 1986:Q2 - 2001:Q1, and another discretionary era from 2001:Q2 to 2006:Q2.

The Markov switching methods identify several regime switches that are not found with the structural change tests. There is an additional discretionary (high deviations) era from 1965:Q4 - 1968:Q4, a short low deviations era from 2006:Q3 - 2007:Q4, and an even shorter high deviations era from 2008:Q1 - 2008:Q4. These differences all occur during the first 15 percent and last 15 percent of the sample, where the Bai and Perron methodology is unable to identify breaks due to the trimming. ${ }^{10}$

According to Figure 5, the division between rules-based and discretionary eras occurs when the Taylor rule deviations equal two percentage points, as almost all of the rules-based eras are when the deviations are below two percent and almost all of the discretionary eras are when the deviations are above two percent. While not an exact metric, it provides a useful benchmark for dividing policy between the eras.

The Markov switching model described above chooses regimes based on switches in both the mean and variance of the Taylor rule deviations. Sims and Zha (2006) and Liu, Waggoner, and Zha (2011) investigate regime switches in U.S. monetary policy and find that their best fitting models do not allow for changes in the inflation target or the coefficients of either the policy rule or the private sector equations, but only in the variances of the structural disturbances. While they estimate changes in monetary policy reaction functions while we

\footnotetext{
${ }^{9}$ The t-statistic for a test that $\mu_{1}=\mu_{2}$ is 12.40 , so the hypothesis that the two coefficients are the same can be rejected at the 1 percent level.

${ }^{10}$ We also estimated Markov switching models with forecasted inflation. Over the same span of data, the results with forecasted inflation are similar to those with realized inflation.
} 
estimate changes in Taylor rule deviations based on a Taylor rule with postulated coefficients, their results suggest that it is worth investigating whether our results for Taylor rule deviations are driven by changes in the mean, the variance, or both.

We estimate two additional versions of the Markov switching model. The first allows the

mean, but not the variance, to switch between the states. This corresponds to the specification of the structural change model, where the breaks are determined solely by the change in the mean of the Taylor rule deviations. The results are reported in Table 5 with the state distribution depicted in Figure 6. Although the correspondence is not exact, the results are broadly consistent with those of the model where both the mean and variance of the Taylor rule deviations are allowed to switch between states, and it is clear that the results from that model are not driven solely by changes in the variance.

The second additional version of the Markov switching model allows both the mean and the variance of the Taylor rule deviations to switch between states, but does not constrain the dates of the mean and variance switches to be the same. The results are reported in Table 6 with the state distribution for the mean and variance illustrated in Figure 7. The state distribution for the mean is broadly consistent with the state distributions of the model where both the mean and variance of the Taylor rule deviations are allowed to switch between states and the model where only the mean is allowed to switch, although the correspondence is again not exact. The state distribution for the variance, in contrast, is very different than any of the state distributions for the mean. It is clear that the division between Taylor rule-based and discretionary eras is driven by changes in the mean, not the variance, of the Taylor rule deviations.

\section{Historical Perspective on our Statistical Results}

Using narrative methods, Taylor (2012a) follows Meltzer (2011) in calling 1985 to 2003 a rules-based era and 2003 - 2012 an ad hoc era. The 1985 start of the rules-based era exactly corresponds to our results with tests for structural change and closely corresponds to our results with Markov switching. The 2003 start of Meltzer's and Taylor's ad hoc eras, however, is two years later than the start of our discretionary era (using both methods). Figure 2 provides visual, as well as statistical, support for dating the start of the ad hoc era in 2001 instead of 2003. While it is clear that the large divergence started in 2003, the actual federal funds rate was below the prescribed rate from 2001 onwards. 
Visual support for dating the start of the ad hoc era in 2001 instead of 2003 is also provided in Figure 8, which depicts the actual federal funds rate and the rate prescribed by the Taylor rule from 1996 to 2006 using real-time CPI inflation and Greenbook output gaps. This figure was introduced by Poole (2007) and reproduced in Taylor (2012a), who used it to justify dating the start of the ad hoc era in 2003. ${ }^{11}$ While it is again clear that the large divergence started in 2003, the actual federal funds rate was below the prescribed rate from 2000 onwards.

Narrative support for dating the start of the ad hoc era in 2001 is also provided by a new book by Justin Lin, former chief economist at the World Bank. Lin (2013) identifies loose monetary policy introduced in 2001 in response to the bursting of the dotcom bubble as a cause of the boom in the U.S. housing market. Taylor (2012b) also dates the start of discretionary policies in the 2000s to the inclusion of a temporary tax rebate in the 2001 tax cuts, although the larger deviations from rules-based policies occurred later.

According to our Markov switching models, there is a rules-based era from 2006:Q3 2007:Q4. Taylor (2007) depicts the actual federal funds rate and an alternative path where the federal funds rate follows a Taylor rule with the coefficients in Equation (2), but smoothed to have 25 basis point increment adjustments. ${ }^{12}$ The actual and alternative paths depart in 2002:Q2 and merge again in 2006:Q3. This is exactly in accord with our results, where the short-lived rules-based era starts in 2006:Q3.

We also identify a final discretionary era from 2008:Q1 to the end of our sample in 2008:Q4. During this period, the federal funds rate was lowered substantially below the prescribed Taylor rule rate. Taylor (2008) proposed subtracting a smoothed version of the LIBOR-OIS spread from the prescribed Taylor rule rate, arguing that such an adjustment, which would have been about 50 basis points in February 2008, would be a more transparent and predictable response to financial market stress than a purely discretionary adjustment. We do not extend the sample further because, once the zero lower bound was attained in December 2008 and the various rounds of quantitative easing started in March 2009, it was no longer appropriate to characterize monetary policy solely by the federal funds rate.

\footnotetext{
${ }^{11}$ The only difference between our figure and the figure in Poole (2007) is that Poole used Congressional Budget Office real-time output gap data starting in 2000:11 because the Greenbook data wasn't publicly available, while we use Greenbook data throughout.

${ }^{12}$ Taylor (2007) reports that using the unsmoothed path in Poole (2007) gives similar results.
} 
The Markov switching models also identify a discretionary era from 1965:Q4 (when the real-time data begins) through 1968:Q4. Narrative support for this statistical result is contained in Taylor (2012b), who argues that while the economic policies of the Kennedy and Johnson administrations (except for the income tax cut of 1964) were "of the temporary, targeted variety", policies of the Nixon administration through mid-1971 followed steadier, long-term, and more predictable precepts. This ended on August 15, 1971, when Nixon imposed wage and price controls, and the interventionist policies continued through the Ford and Carter administrations. This is in accord with the results of our Markov switching models, where a rules-based era first replaced a discretionary era in 1969:Q1, exactly coinciding with the start of the Nixon administration. Our methods, however, do not date the end of the rules-based era until 1974:Q3.

\section{Conclusions}

The superiority of rules versus discretion has been a recurring theme for the conduct of monetary policy for over 30 years. During the past 20 years, the most common metric for monetary policy evaluation has been the Taylor rule where, in its original form, the prescribed federal funds interest rate is equal to 1.0 plus 1.5 times the inflation rate plus 0.5 times the output gap. Periods in which the federal funds rate adhered relatively closely to the Taylor rule prescribed rate, notably the mid-1980s and the 1990s, are often associated with good economic outcomes while periods in which the federal funds rate was further removed from the Taylor rule prescribed rate, notably the 1970s and (more controversially) the early-to-mid 2000s, are often associated with bad economic outcomes.

The purpose of this paper is to identify (Taylor) rules-based and discretionary eras from the data rather than choosing them a priori. Choosing the dates of the eras endogenously is important because, if they are picked exogenously, there is always the possibility that knowledge of subsequent economic outcomes will influence the choice of the dates. We define Taylor rulesbased and discretionary eras by smaller and larger Taylor rule deviations, the absolute value of the difference between the actual federal funds rate and the federal funds rate prescribed by the original Taylor rule, and use tests for multiple structural changes and Markov switching models to identify the eras. 
Monetary policy in the U.S. is characterized by a Taylor rules-based (low deviations) era until 1974, a discretionary (high deviations) era from 1974 to about 1985, a rules-based era from about 1985 to 2000, and a discretionary era from 2001 to 2008. The Taylor rule deviations are about three times as large in the discretionary eras than in the rules-based eras and are almost four times larger in the most discretionary era (1974 to 1984) than in the least discretionary era (1985 to 2000). These results are very similar between the two methods. With the Markov switching models, which allow for regime changes at the beginning and end of the sample, we also identify a rules-based era from 1965 to 1968 and a discretionary era in 2006 and 2007. The discretionary and rules-based eras closely correspond to periods where the Taylor rule deviations are above and below two percent.

These results both accord with and reinforce previous work that identifies monetary policy eras less formally. Meltzer (2011) and Taylor (2012a) call 1985 to 2003 a rules-based era and 2003 - 2012 an ad hoc era, Taylor (2007) emphasizes the large Taylor rule deviations from 2002 to 2006, Poole (2007) depicts Taylor rule deviations starting in 2001, and Taylor (2012b) discusses the transition from discretionary policymaking during the Kennedy and Johnson administrations through 1968 to more rules-based policymaking at the start of the Nixon administration in 1969. In contrast to previous work, however, our results are not subject to the criticism that the choice of eras was influenced by subsequent outcomes. They therefore provide a better basis to evaluate whether "monetary policy rules work and discretion doesn't." 13

\footnotetext{
${ }^{13}$ Taylor (2012a), page 1017.
} 


\section{References}

Bai, Jushan and Pierre Perron (1998), "Estimating and Testing Linear Models With Multiple Structural Changes," Econometrica, 66, 47-78.

Bai, Jushan and Pierre Perron (2003a), "Computation and Analysis of Multiple Structural Change Models," Journal of Applied Econometrics, 18, 1-22.

Bai, Jushan and Pierre Perron (2003b), "Critical Values for Multiple Structural Change Tests," Econometrics Journal, 6, 72-78.

Croushore, Dean, and Tom Stark (2011), “A Real-Time Data Set for Macroeconomists,” Journal of Econometrics, 105, November, 111-130.

Economic Report of the President (1983), U.S. Government Printing Office, Washington, D.C.

Gordon, Robert J. (1984), "Unemployment and Potential Output in the 1980s,"Brookings Papers on Economic Activity, 15, 537-564.

Hamilton, James, 1989, "A New Approach to the Economic Analysis of Nonstationary Time Series and the Business Cycle," Econometrica, vol. 57(2), pages 357-384.

Kydland, Finn E. and Edward C. Prescott (1977), "Rules Rather than Discretion: The Inconsistency of Optimal Plans," The Journal of Political Economy, Vol. 85, No. 3, 473-492.

Lin, Justin (2013), "Against the Consensus: Reflections on the Great Recession," Cambridge University Press

Liu, Zheng, Waggoner, Daniel, and Tao Zha (2011), "Sources of Macroeconomic Fluctuations: A Regime-Switching DSGE Approach," Quantitative Economics, 2, 251-301.

Meltzer, Allan H. (2011), "Federal Reserve Policy in the Great Recession." Remarks presented at Cato Institute Monetary Conference, November.

Nikolsko-Rzhevskyy, Alex and David Papell (2012), "Taylor Rules and the Great Inflation," Journal of Macroeconomics, Volume 34, Issue 4, 903-918.

Orphanides, A. (2001), "Monetary Policy Rules Based on Real-Time Data," American Economic Review, 91(4), September, 964-985.

Perron, Pierre and Zhongjun Qu (2006), "Estimating restricted structural change models," Journal of Econometrics, Elsevier, vol. 134(2), 373-399.

Poole, William (2007), “Understanding the Fed," Federal Reserve Bank of St. Louis Review 89, 3-13. 
Sims, Christopher and Tao Zha (2006), "Were There Regime Switches in U.S. Monetary Policy?” American Economic Review, 96(1), 54-81.

Taylor, John B. (1993), "Discretion versus Policy Rules in Practice." Carnegie Rochester Conference Series on Public Policy 39, 195-214.

Taylor, John B. (1999), “An Historical Analysis of Monetary Policy Rules," in Monetary Policy Rules, University of Chicago Press, 319-348.

Taylor, John B. (2007), "Housing and Monetary Policy,” In Housing, Housing Finance, and Monetary Policy, Proceedings of FRB of Kansas City Symposium, Jackson Hole, WY, September, pp. 463-76.

Taylor, John B. (2008), "The Costs and Benefits of Deviating from the Systematic Component of Monetary Policy," Keynote Address at the Federal Reserve Bank of San Francisco Conference on "Monetary Policy and Asset Markets", February 22, 2008

Taylor, John B. (2012a), "Monetary Policy Rules Work and Discretion Doesn't: A Tale of Two Eras," Journal of Money, Credit and Banking, Vol. 44, No. 6, 1017-1032.

Taylor, John B. (2012b), "First Principles: Five Keys to Restoring America's Prosperity,” W. W. Norton \& Company. 


\section{Table 1. Bai and Perron Tests for Multiple Structural Changes}

$d_{t}=\gamma_{0}+\gamma_{1} D U_{1 t}+\gamma_{2} D U_{2 t}+\gamma_{3} D U_{3 t}+u_{t}$

\begin{tabular}{|c|c|c|c|}
\hline $\begin{array}{c}\text { SupF test } \\
\text { (sequential method) }\end{array}$ & $\begin{array}{c}\text { Critical values } \\
\qquad(1 \%)\end{array}$ & $\begin{array}{l}\text { Break } \\
\text { dates }\end{array}$ & 95\% Confidence Intervals \\
\hline $\operatorname{SupF}(1 \mid 0)=31.12^{*}$ & 12.29 & 1985:Q1 & 1984:Q4 - 1986:Q2 \\
\hline $\operatorname{SupF}(2 \mid 1)=50.12 *$ & 13.89 & 2001:Q1 & 1999:Q2 - 2001:Q3 \\
\hline $\operatorname{SupF}(3 \mid 2)=48.42 *$ & 14.80 & 1974:Q3 & 1972:Q3 - 1975:Q2 \\
\hline \multicolumn{4}{|c|}{ Coefficients } \\
\hline \multicolumn{4}{|c|}{$\gamma_{0}=1.468$} \\
\hline \multicolumn{4}{|c|}{$\gamma_{1}=1.836$} \\
\hline \multicolumn{4}{|c|}{$\gamma_{2}=-2.458$} \\
\hline \multicolumn{4}{|c|}{$\gamma_{3}=1.455$} \\
\hline
\end{tabular}

Note: The results are based on a value of the trimming parameter $\varepsilon=0.15$ and a maximum number of breaks $m=5$.

Table 2. Perron and Qu Tests for Multiple Restricted Structural Changes

$$
d_{t}=\gamma_{0}+\gamma_{1} D U_{1 t}+\gamma_{2} D U_{2 t}+\gamma_{3} D U_{3 t}+u_{t}, \quad \gamma_{1}+\gamma_{2}=0 \text { and } \gamma_{2}+\gamma_{3}=0
$$

\begin{tabular}{|c|c|c|c|}
\hline Restricted SupF test & $\begin{array}{c}\text { Critical value } \\
(1 \%)\end{array}$ & $\begin{array}{c}\text { Break } \\
\text { dates }\end{array}$ & $95 \%$ Confidence Intervals \\
\hline \multirow{2}{*}{$99.93^{*}$} & 17.82 & $1985: \mathrm{Q} 1$ & $1984: \mathrm{Q} 4-1987: \mathrm{Q} 2$ \\
\cline { 2 - 4 } & $2001: \mathrm{Q} 1$ & $1999: \mathrm{Q} 3-2001: \mathrm{Q} 2$ \\
\cline { 2 - 4 } & $1974: \mathrm{Q} 3$ & $1972: \mathrm{Q} 2-1975: \mathrm{Q} 2$ \\
\hline \multicolumn{3}{|c|}{$\gamma_{0}=1.075$} \\
\hline \multicolumn{3}{|c|}{$\gamma_{1}=1.805$} \\
\hline & $\gamma_{2}=-1.805$ \\
\hline
\end{tabular}




$$
\gamma_{3}=1.805
$$

Note: The results are based on a value of the trimming parameter $\varepsilon=0.15$ and a maximum number of breaks $m=5$. 
Table 3. Bai and Perron Tests for Multiple Structural Changes with Inflation Forecasts $d_{t}=\gamma_{0}+\gamma_{1} D U_{1 t}+\gamma_{2} D U_{2 t}+\gamma_{3} D U_{3 t}+u_{t}$

\begin{tabular}{|c|c|c|c|}
\hline $\begin{array}{c}\text { SupF test } \\
\text { (sequential method) }\end{array}$ & $\begin{array}{c}\text { Critical values } \\
(1 \%)\end{array}$ & $\begin{array}{c}\text { Break } \\
\text { dates }\end{array}$ & 95\% Confidence Intervals \\
\hline SupF(1| 0) $=54.08^{*}$ & 12.29 & $1985: \mathrm{Q} 3$ & $1985: \mathrm{Q}-1986: \mathrm{Q} 3$ \\
\hline SupF(2| 1) =61.42* & 13.89 & $2001: \mathrm{Q} 1$ & $2000: \mathrm{Q} 1-2001: \mathrm{Q} 3$ \\
\hline SupF(3| 2) $=54.78^{*}$ & 14.80 & $1980: \mathrm{Q} 3$ & $1977: \mathrm{Q}-1982: \mathrm{Q} 2$ \\
\hline \multicolumn{3}{|c|}{ Coefficients } \\
\hline \multicolumn{3}{|c|}{$\gamma_{0}=2.339$} \\
\hline \multicolumn{3}{|c|}{$\gamma_{1}=1.856$} \\
\hline \multicolumn{3}{|c|}{$\gamma_{2}=-3.516$} \\
\hline
\end{tabular}

Note: These tests use Greenbook inflation forecasts from 1973:Q3 - 2007:Q4. The results are based on a value of the trimming parameter $\varepsilon=0.15$ and a maximum number of breaks $m=5$. 
Table 4. Markov Switching Model: Switching Mean and Variance

\begin{tabular}{|c|c|c|}
\hline & $\begin{array}{c}\text { State } \mathrm{s}=1 \\
\text { (Rule-based policy) }\end{array}$ & $\begin{array}{c}\text { State } \mathrm{s}=2 \\
\text { (Discretion) }\end{array}$ \\
\hline$\mu_{\mathrm{s}}$ & 0.809 & 2.918 \\
& $(0.072)$ & $(0.155)$ \\
\hline$\sigma_{\mathrm{s}}$ & 0.566 & 1.209 \\
& $(0.052)$ & $(0.101)$ \\
\hline$p_{\mathrm{ss}}$ & 0.960 & 0.953 \\
& $(0.024)$ & $(0.024)$ \\
\hline
\end{tabular}

Table 5. Markov Switching Model: Switching Mean, Constant Variance

\begin{tabular}{|c|c|c|}
\hline \multirow{2}{*}{$\mu_{\mathrm{s}}$} & $\begin{array}{c}\text { State } \mathrm{s}=1 \\
\text { (Rule-based policy) }\end{array}$ & $\begin{array}{c}\text { State } \mathrm{s}=2 \\
\text { (Discretion) }\end{array}$ \\
& 0.945 & 3.174 \\
& $(0.101)$ & $(0.143)$ \\
\hline$\sigma_{\mathrm{s}}$ & \multicolumn{3}{|c|}{0.891} \\
& 0.937 & $(0.051)$ \\
\hline$p_{\mathrm{ss}}$ & $(0.033)$ & 0.952 \\
& & \\
\end{tabular}

Table 6. Markov Switching Model: Switching Mean and Independently Switching Variance

\begin{tabular}{|c|c|c|}
\hline & $\begin{array}{c}\text { State } \mathrm{s}=1 \\
\text { (Rule-based policy) }\end{array}$ & $\begin{array}{c}\text { State } \mathrm{s}=2 \\
\text { (Discretion) }\end{array}$ \\
\hline$\mu_{\mathrm{s}}$ & 0.816 & 2.655 \\
& $(0.074)$ & $(0.106)$ \\
\hline$\sigma_{\mathrm{s}}$ & 0.606 & 1.905 \\
& $(0.041)$ & $(0.326)$ \\
\hline$p_{\text {sean }}^{\text {ss }}$ & 0.979 & 0.953 \\
& $(0.022)$ & $(0.031)$ \\
\hline$p^{\text {var }}$ ss & 0.935 & 0.951 \\
& $(0.031)$ & $(0.034)$ \\
\hline
\end{tabular}


Figure 1. Real-time Output Gaps using Linear, Quadratic, and Hodrick-Prescott Detrending

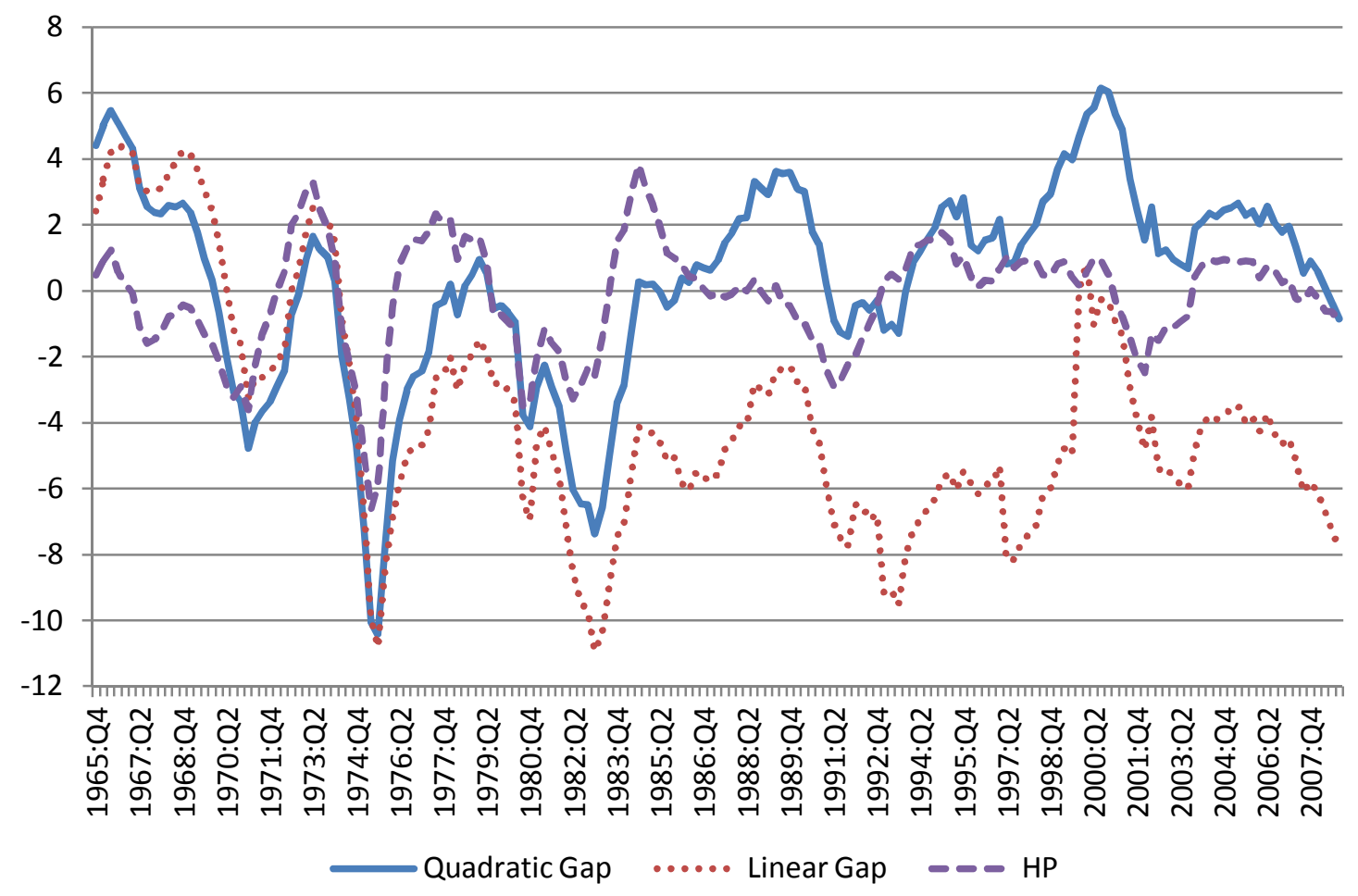




\section{Figure 2.}

Panel A. The Federal Funds Rate and the Implied Taylor Rule Rate

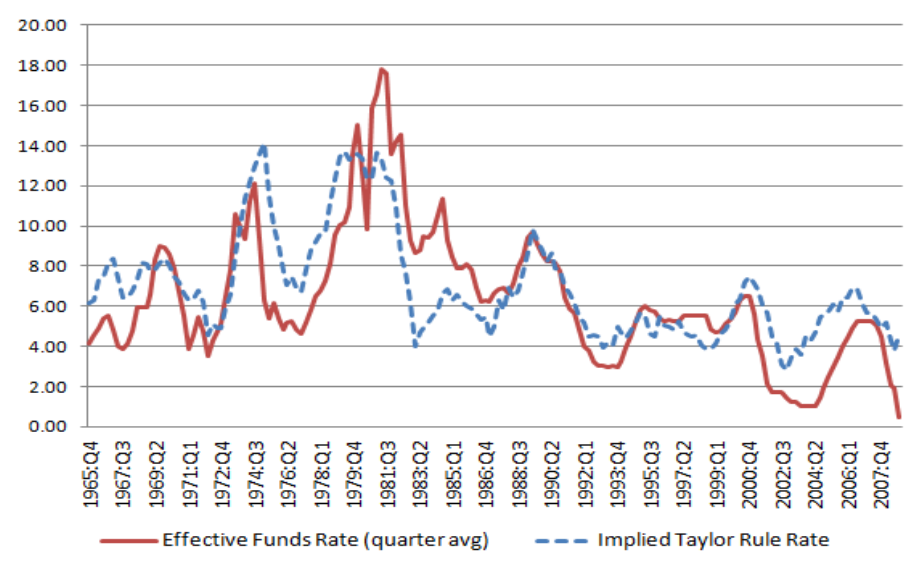

Panel B. The Difference between the Actual and Implied Rates

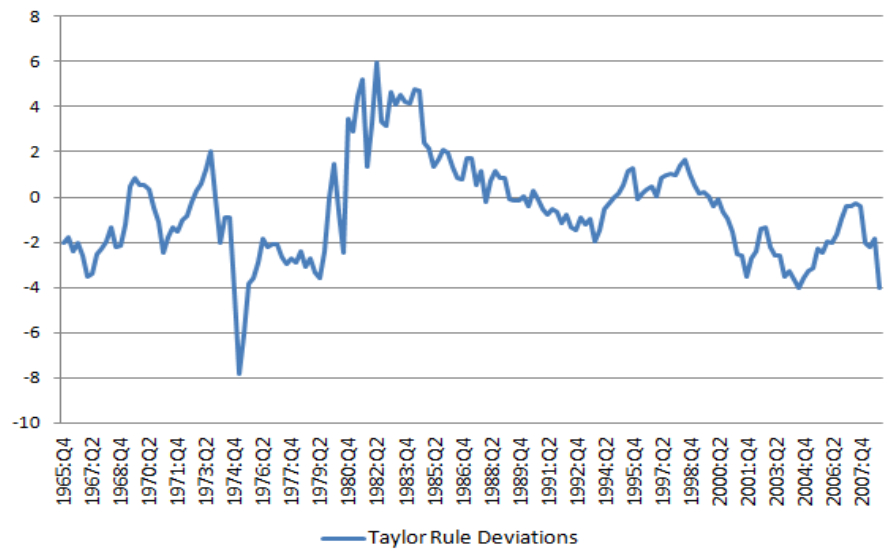

Panel C. Taylor Rule Deviations (Absolute Value)

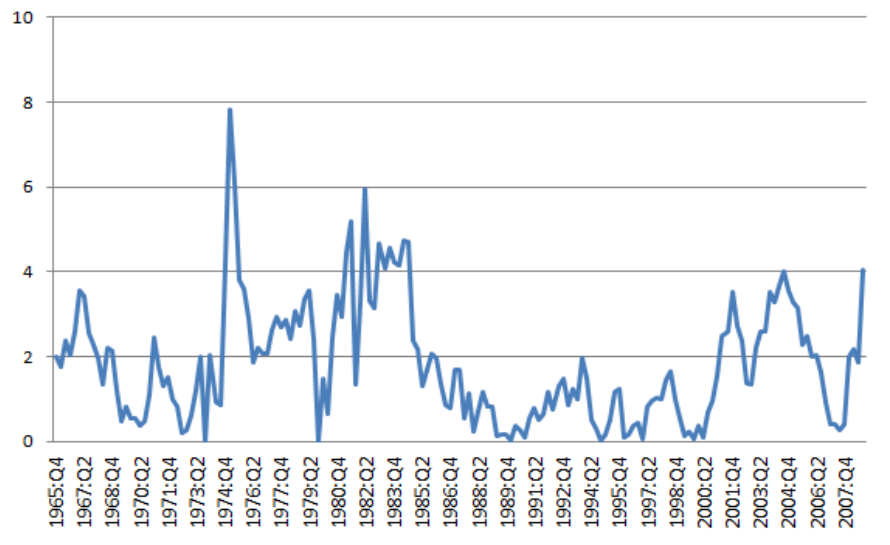


Figure 3. Structural Change Tests for Taylor Rule Deviations

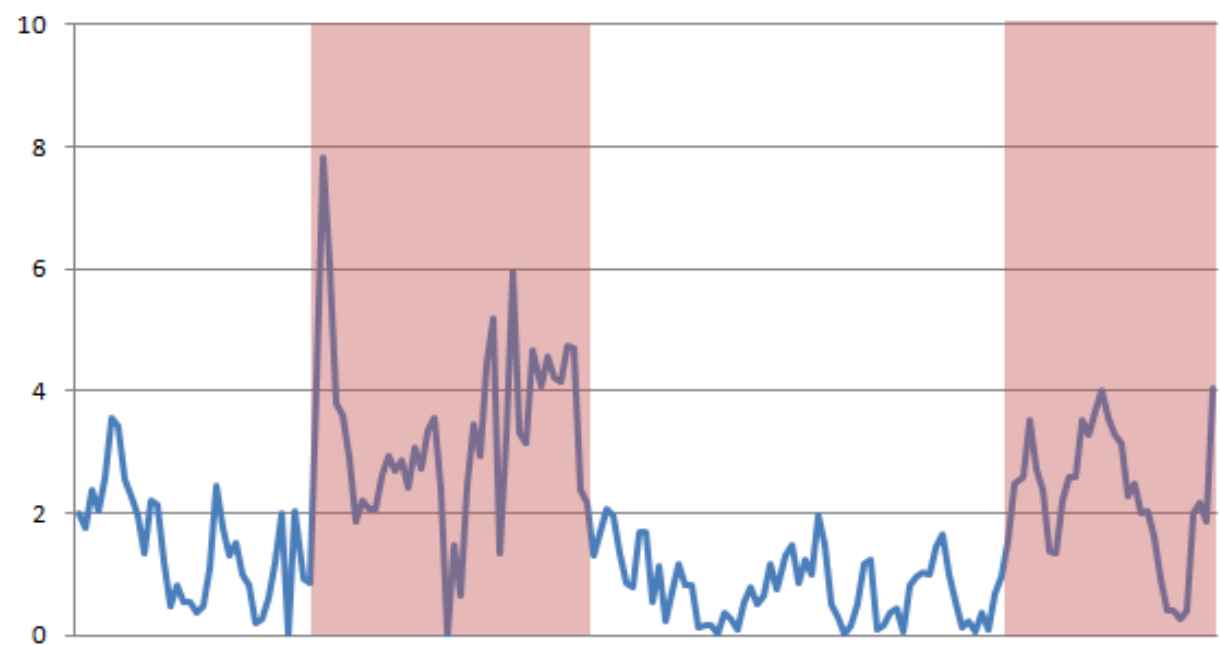

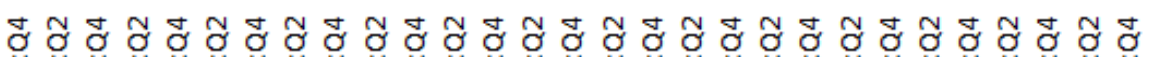

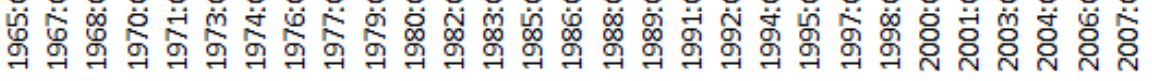

—Taylor Rule Deviations (absolute value)

Figure 4. Structural Change Tests with Four-Quarter-Ahead Greenbook Inflation Forecasts

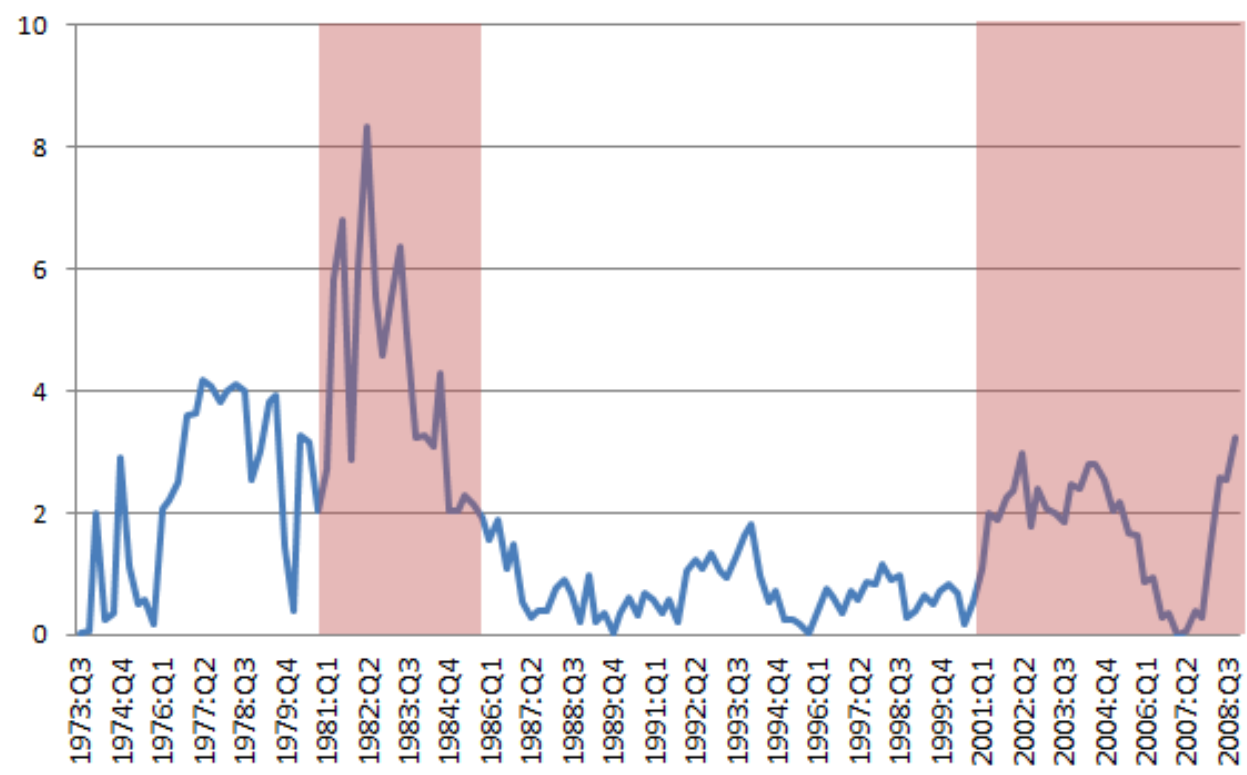

_Taylor Rule Deviations (absolute value) 
Figure 5. Markov Switching Model: Switching Mean and Variance

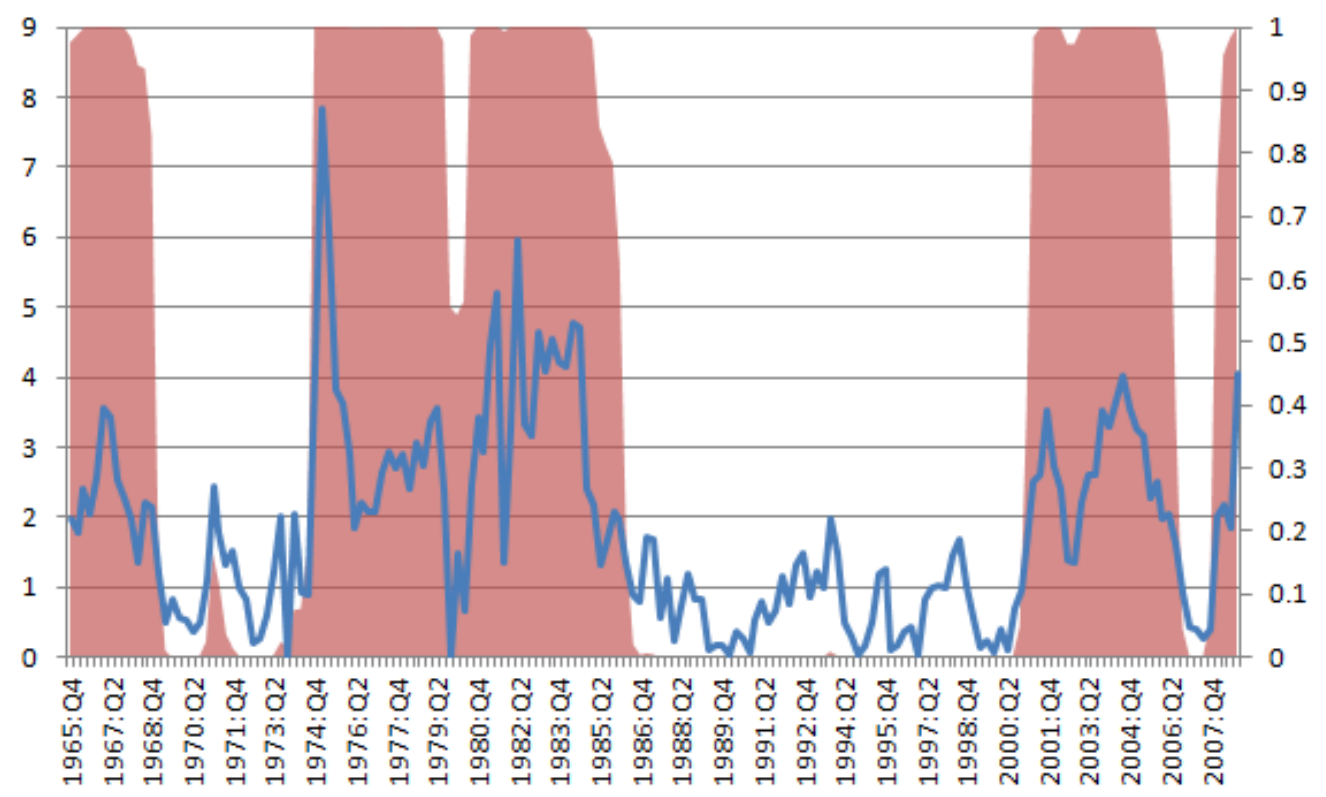

Figure 6. Markov Switching Model: Switching Mean, Constant Variance

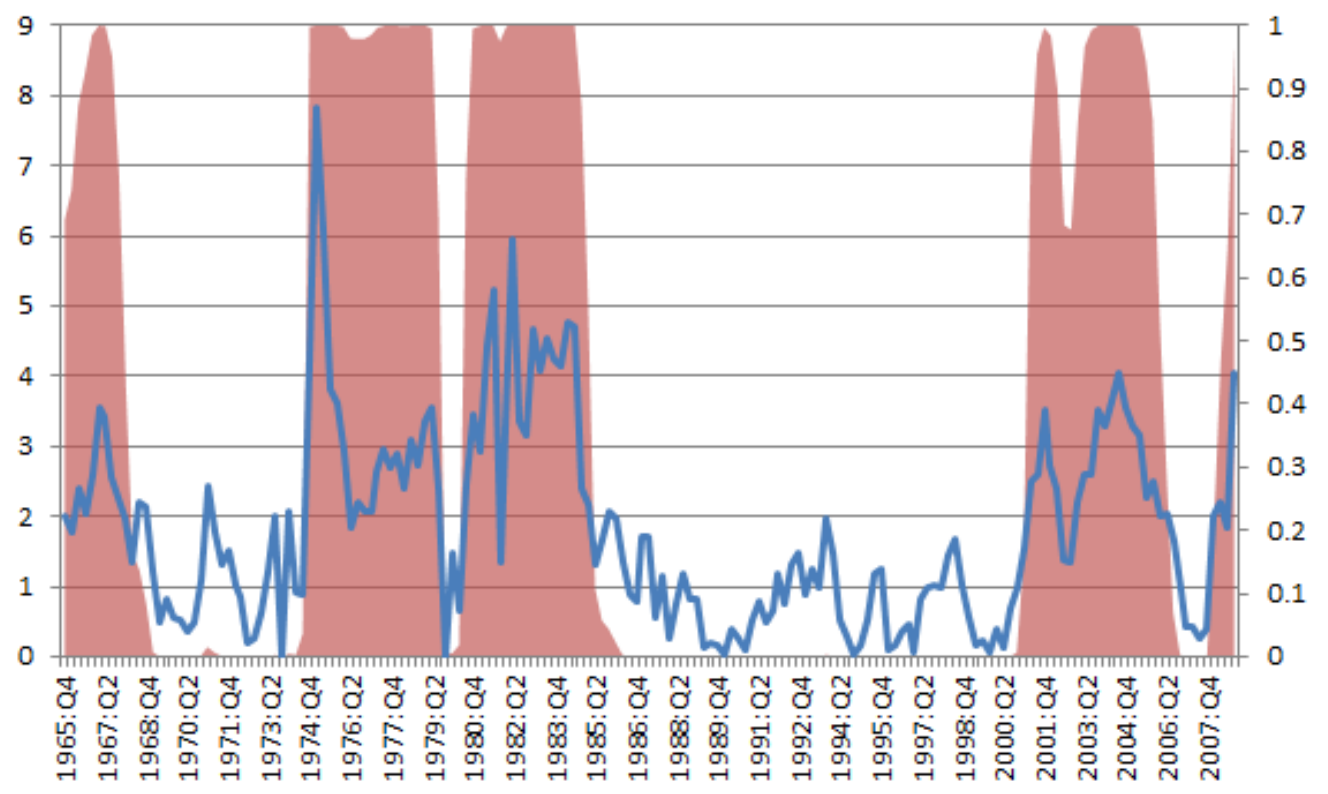

Probability of the Descretionary State Taylor rule deviations (absolute value) 
Figure 7. Markov Switching Model: Independently Switching Mean and Variance

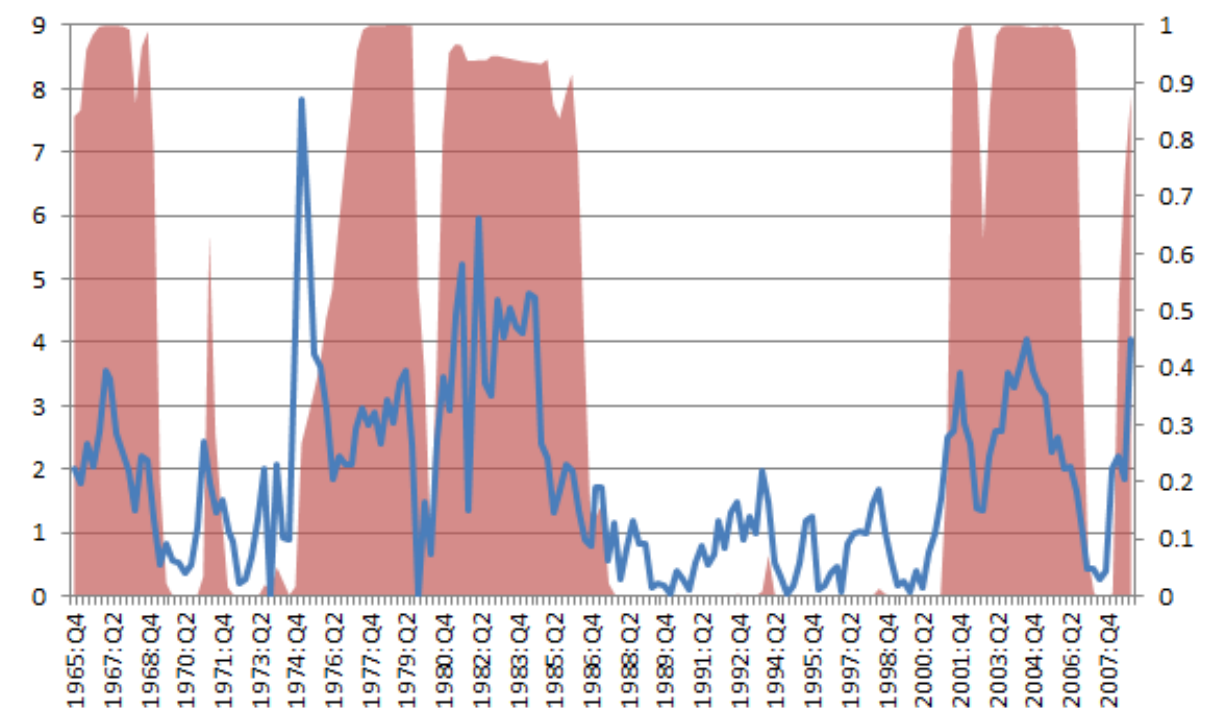

Probability of the Descretionary State -Taylor rule deviations (absolute value)

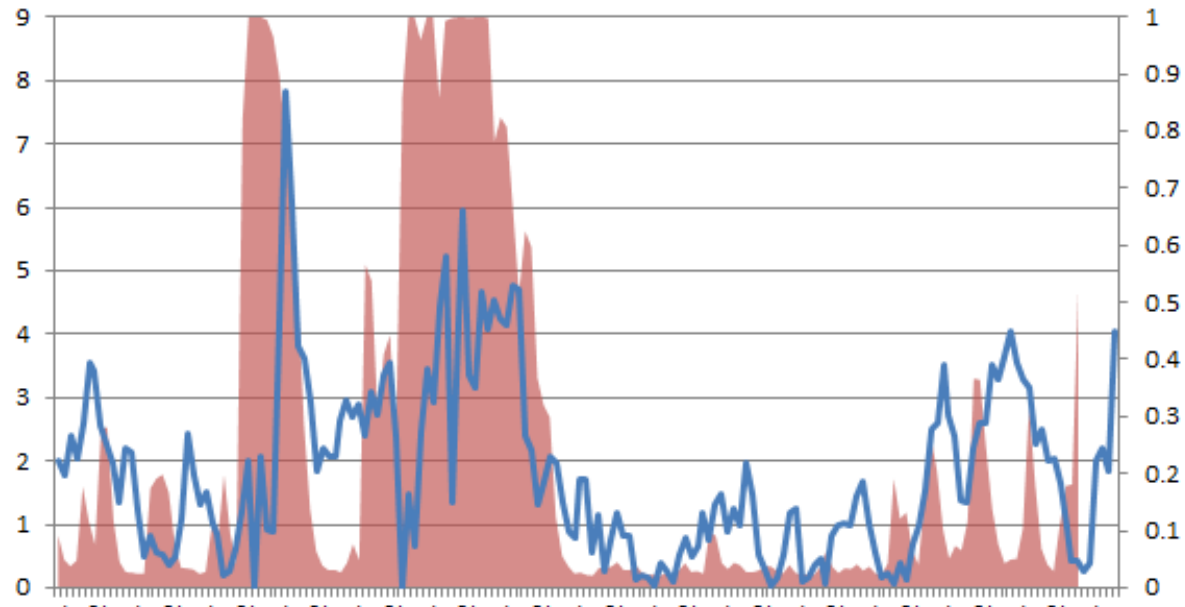

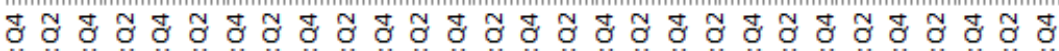

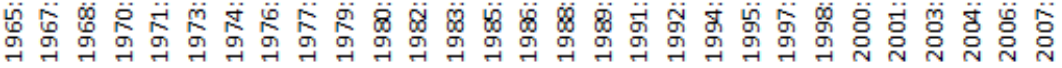

Probability of the High-Variance State _-Taylor rule deviations (absolute value) 
Figure 8. Actual and Prescribed Rates from 1996 to 2006 using Greenbook Output Gaps

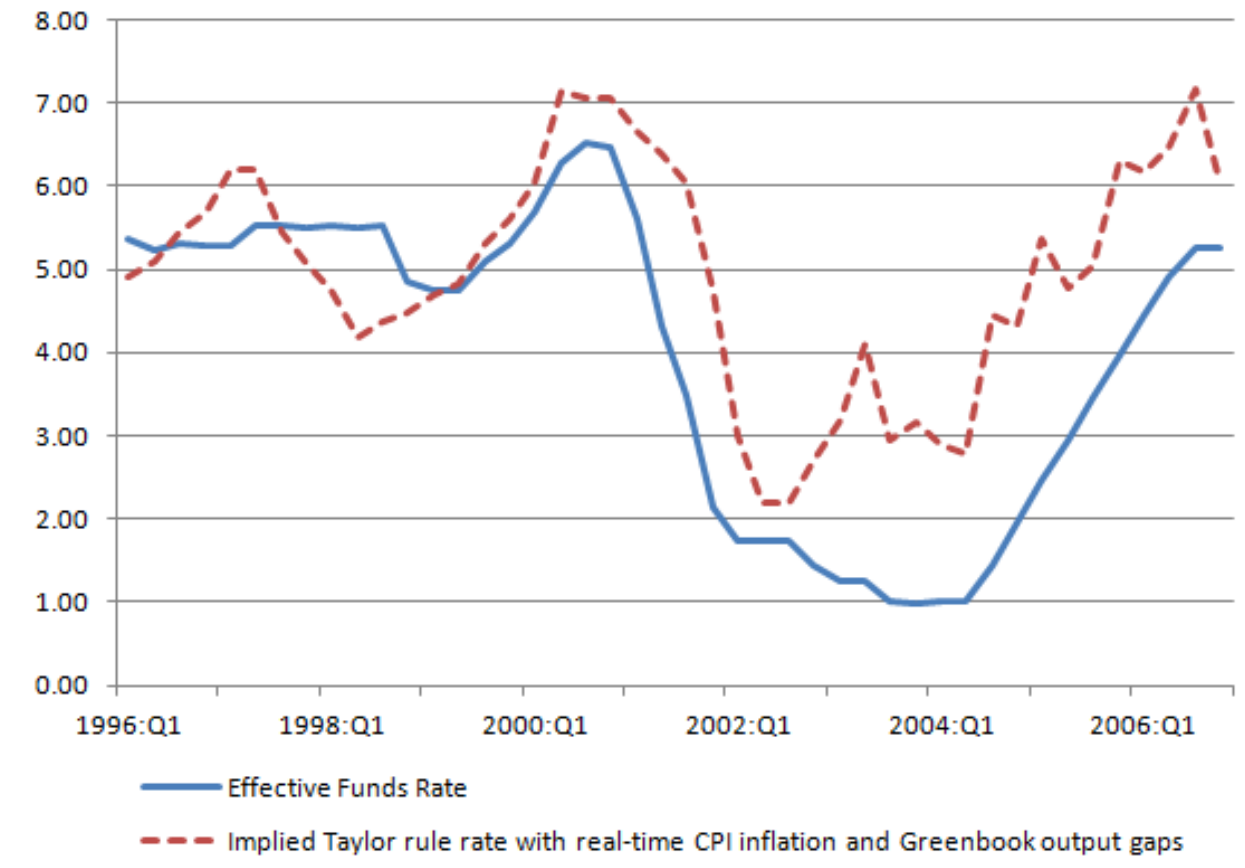

